\title{
Digital Transformation in Electrical Equipment Manufacturing Enterprises
}

\author{
Nguyen Thi Thanh DAN ${ }^{1 *}$ and Nguyen Quang CHUONG ${ }^{2}$ \\ Department of Management Science and Law, School of Economics and Management, Hanoi University of Science and \\ Technology, Hanoi, Vietnam \\ *Corresponding author: dan.nguyenthithanh@hust.edu.vn
}

\begin{abstract}
The study of digital transformation as the key to the implementation of a digital economy is a matter of utmost concern for businesses around the world. This study systematizes the theoretical basis of digital transformation in manufacturing enterprises, and on that basis, analyzes the current situation of digital transformation of manufacturing enterprises in general and electrical equipment manufacturing enterprises in particular, and lastly provide lessons for electrical equipment manufacturing enterprises in Hanoi. The analysis results show that electrical equipment manufacturing enterprises are at the beginning of digital transformation. Overall, companies show the highest levels of digital readiness in forward and backward linkages. The study also provides recommendations for businesses in the process of implementing digital transformation and recommendations on the state's macro policies in creating favorable conditions for businesses to successfully implement digital transformation in the future.
\end{abstract}

Research purpose:

This study systematizes the theoretical basis of digital transformation in manufacturing enterprises, and on that basis, analyzes the current situation of digital transformation of manufacturing enterprises in general and electrical equipment manufacturing enterprises in particular, and lastly provide lessons for electrical equipment manufacturing enterprises in Hanoi

Research motivation:

The study of digital transformation as the key to the implementation of the digital economy is a matter of utmost concern for businesses around the world. Digital transformation is more and more developed and applied in the manufacturing industry thanks to its benefits.

Research design, approach and method:

The author systematizes the theory of digital transformation, especially in the field of production. The study conducted a survey for 20 electrical equipment manufacturing enterprises in Hanoi to assess the digital transformation situation of this enterprise, thereby proposing some recommendations to promote the digital transformation of enterprises.

Main findings:

The analysis results show that electrical equipment manufacturing enterprises are at the beginning of digital transformation. Overall, companies show the highest levels of digital readiness in forward and backward linkages.

Practical/managerial implications:

The study also provides recommendations for businesses in the process of implementing digital transformation and recommendations on the state's macro policies in creating favorable conditions for businesses to successfully implement digital transformation in the future.

Keywords: Digital transformation, enterprises, manufacturing, electrical equipment

\section{INTRODUCTION}

Digital transformation is currently a matter of concern for the state, ministries, sectors, businesses and researchers. Digital transformation is ongoing and holds great promise to drive innovation, create efficiency and improve services, and drive productivity gains. Digital technologies also make it easier for people to participate in economic and social activities. However, those benefits come with new challenges as digital transformation changes the nature and structure of organizations, markets and communities, and raises employment and technical concerns, privacy and security, as well as the concept of equity and integration. A big problem is that we are often not ready to accept changes imposed by old thinking and habits ( Vu Minh Khuong, 2019). Previous studies have shown a society's lack of readiness for dramatic changes in technology. Researching the awareness and readiness of businesses for digital transformation is an urgent issue, because digital transformation is not simply an effort to invest in information technology application but a comprehensive and profound reform in order to fully exploit the power of the times and technological advances to improve efficiency, competitiveness and create a basic foundation for a long-term development journey. 
Meanwhile, the manufacturing industry is an important industry and is the driving force for national economic growth in general - increasing by more than $14 \%$ in 2017. This is also a highly profitable industry from Industry 4.0. However, labor productivity in Vietnam's manufacturing sector is very low compared to other East Asian countries. Therefore, this sector is where digitization can be most profitable for production, business and productivity efficiency. On the other hand, the manufacturing sector has the major employees in the Vietnamese economy, accounting for over $30 \%$ of the total Industry 4.0 workforce and the introduction of industry-wide automation will create a significant shift in the workforce, especially in jobs that regularly account for a high proportion of the sector. Understanding the challenges of this transition are very important for Vietnamese businesses especially those in mitigating the labor market impact of Industry 4.0 policies and applying new digital technologies. The study of the digital transformation situation of equipment manufacturing enterprises is of theoretical and practical significance for research enterprises and other manufacturing enterprises, necessary for successful implementation transition to the digital economy in the future.

Currently, most executives are preoccupied with trying to understand how the digital revolution is affecting and will continue to affect their companies in the context of an ongoing pattern shift from an industrial economy to a digital economy (Thomas M. Siebel, 2019). In some industries, such as retail, profits for large companies are falling, despite efforts to stem the decline. Until now, the dominance of leading manufacturing companies has not been threatened to the same extent. These companies are highly vertically integrated and often compete on the basis of their technology (including products) and production functions and costly complementary assets in the value chain (Joakim Björkdahl, 2020). ; K. Liere-Ntheler et al., 2018). The right digital management needs to provide them with the opportunity to improve their creativity and capture value associated with the digital revolution. But what do established manufacturing companies and their CEOs need to do to reap the benefits of digital technology and data? Several studies aim to shed light on the digitization efforts of established large manufacturing companies, the challenges involved and how to manage them (Joakim Björkdahl, 2020)

Studies show that technology is not the issue that keeps business leaders engaged in digitization efforts. The development and use of new digital technologies is a prerequisite for digital transformation, but not sufficient for success. Successful efforts require re-optimization to enable efficient use of digital technologies and data, and to create and capture value in new ways. This may require new organizational forms and new ways of working to build the capacity to perceive, shape and seize opportunities (A. Bharadwaj et al., 2013; L. Caldwell, 2018); Alp Ustundag and Emre Cevikcan, 2018). In other words, it takes more than just digital technology and data for digital transformation to be successful and effective. If manufacturing enterprises do not take full control of their digitization efforts in terms of developing and transforming their methods, strategies and organizations, they risk losing opportunities to create profits and are left out by others (T. Hess et al., 2016; Christian Matt et al., 2015; O. Aguilar and J. Girzadas, 2019, T. Hess et al., 2016). The study of digital transformation to lead to the implementation of the digital economy is a matter of special concern for businesses around the world.

\section{THEORETICAL FOUNDATIONS OF DIGITAL TRANSFORMATION AND DIGITAL TRANSFORMATION OF MANUFACTURING ENTERPRISES}

\subsection{Concepts}

Digital transformation is the general trend of the 4.0 era. But there is no universal definition for the concept of digital transformation. For each business and organization with different management models and methods, the definition of digital transformation is also different:

Digital Transformation by Thomas M. Siebel: The c onfluence of four technologies - elastic cloud computi ng, big data, artificial intelligence, and the internet of things, which is fundamentally changing how busine ss and government will operate in the 21 st century ( Thomas M. Siebel, 2019)

For FSI - Vietnam's leading digital transformation enterprise: Digital transformation in an organization is the process of changing from a traditional model to a digital enterprise by applying new technologies such as cloud computing, big data, Internet of things, ... changing operating methods, leadership, working processes, company culture... (Danang city Web potal, 2020)

According to many studies, Digital transformation is the ability of an organization to "adapt, respond, and position itself for success in the face of rapid technology evolution" (Guinan, Parise, \& Langowitz, 2019) which is changing the way businesses operate around the world (Chen, Ravichandar, \& Proctor, 2016; Matt, Hess, $\&$ Benlian, 2015). However, the essence of digital transformation is the creation of a new production method based on technology and digital data and gradually converting to that method. And for successful 
digital transformation, besides the application of new digital technologies and data, businesses need to build a comprehensive and appropriate digital transformation process.

\subsection{The importance of digital transformation}

Reports of large market research companies such as Gartner, IDC... all show that digital transformation really brings a lot of benefits to all aspects of business activities: from management to research. , business... (Danang city Web potal, 2020). The most recognizable benefits of digital transformation for businesses are cutting operating costs, reaching more customers in a longer period of time, leadership making decisions more quickly and accurately thanks to a timely and transparent reporting system, optimizing employee productivity... these things help increase operational efficiency and improve the competitiveness of organizations and businesses. According to the statistics of the Ministry of Science and Technology, the reasons why manufacturing enterprises should transform digitally: environmental benefits, risk management, improving the efficiency of equipment use, management efficiency, etc. value, saving input and increasing output (Figure 1)

\section{Manufacturing firms}

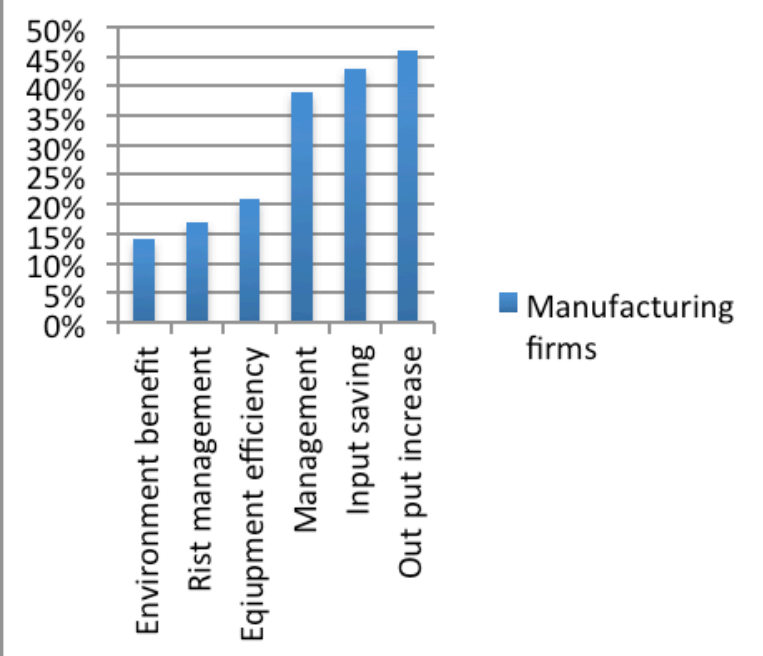

Figure 1: Reasons given as to why enterprises should adopt digital technologies

Source: Ministry of Science and Technology analysis

Taking advantages of technology platforms will help businesses improve many areas and reach the ultimate goals of digital transformation. Whereas for ordinary people, digital transformation changes the way we live, work and transact with each other. As for the state, digital transformation uses data and digital technology to change the user experience with services provided by the state, change business processes, change the model and mode of operation of the government state management agency.

Digital transformation also contributes to increasing labor productivity. Microsoft research shows that, in 2017, the impact of digital transformation on labor productivity growth was about $15 \%$, by 2020 , this figure will be $21 \%$

In general, according to market research and analysis experts, the 5 ultimate goals that digital transformation businesses aim for include: Speeding to market; Strengthening competitive position in the market; Drive revenue growth; Increase employee productivity; Expand your ability to attract and retain customers

2.3 Conditions and difficulties in digital transformation of manufacturing enterprises

Four important elements of digital transformation (Microsoft Vietnam Communications, 2021), which are:

Vision \& Strategy: The mission of businesses is not simply how to return to normal, but how to be more resilient in a changed world. Vision is expressed through strategy. Businesses need to think beyond what they think is possible - especially in a time when speed and agility are essential to survival.

Culture: Culture supports strategy and vision, and activates and empowers employees. Digital transformation organizations succeed when all employees unite and work on the values and vision they share. They need access to new ideas, processes and technologies - which is what is needed to build resilience.

Distinctive potential: Businesses that discover the distinctive potential of the organization will respond and adapt to circumstances more easily. Every organization has potential, but it's important to find a specific point of difference - a key point - that can set your business apart in a whole new way.

Competence: It is a combination of human capacity and technological competence. Businesses need human resources equipped with the right skills to make the transformation. They also need appropriate and secure technology platforms with the ability to empower employees to remotely access and grow the business under any circumstances.

Mr. Pham The Truong, General Director of Microsoft Vietnam, said that "The combination of people and technology within an organization will create new opportunities for businesses. Applying technology is only the first step for an organization to transform into a digital business. To be successful, businesses need to have a vision, strategy, organizational culture, and the distinctive potential. Businesses that meet these four factors will take the lead in digital transformation, 
improve competitiveness, and create different products, services, and business models in the new era" (Microsoft Vietnam Communications, 2021).

The biggest challenges in digital transformation of manufacturing enterprises are: Lack of information, Finance Shortage, Technology identification, incompatible equipment and not useful (see Figure 2)

\section{Manufacturing firms}

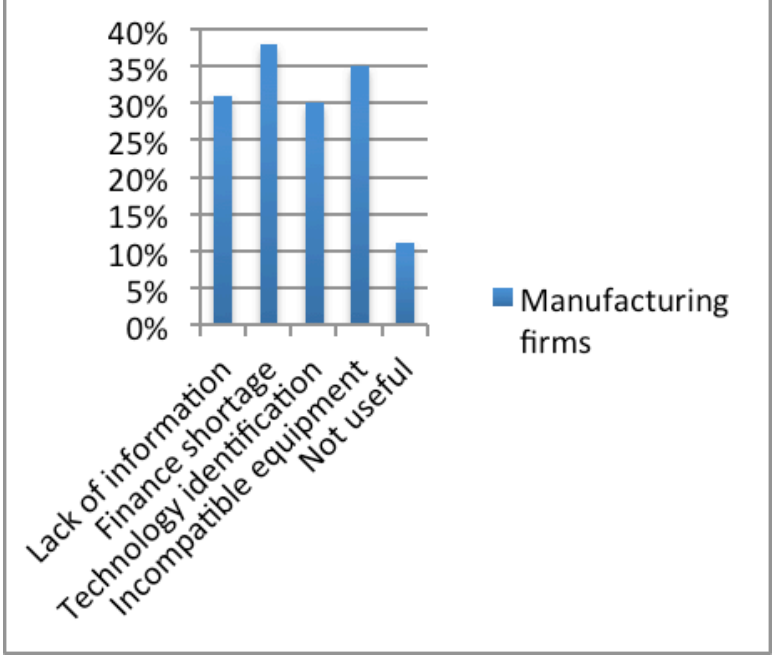

Figure 2. Top challenges to digitalization in manufacturing firms

Source: Ministry of Science and Technology analysis

\section{SITUATION OF DIGITAL TRANSFORMATION OF ELECTRICAL EQUIPMENT MANUFACTURERS}

Digital transformation is more and more developed and applied in the manufacturing industry because of the benefits it brings. To have an assessment of the digital transformation situation of electrical equipment manufacturing enterprises, the author conducted a survey on the digital transformation situation in 20 small and medium-sized electrical equipment enterprises in the following fields: Human (Digital skills and capabilities), Finance, Strategy, Smart production and Infrastructure.

The data in this study was collected in electrical equipment manufacturing enterprises operating in Hanoi. The objects of survey are the middle or senior managers of these enterprises. The survey conducted in August 2021. The survey results are shown as:

Digital skills and capabilities: About $90 \%$ of electrical equipment manufacturing enterprises are small and medium-sized enterprises, with characteristics of producing single products, small quantities, and diverse product categories. According to the author's survey, over $20 \%$ of businesses said they have enough Information Communication Technology (ICT) skills to effectively maintain and use their digital systems, while the rest of the businesses said that they have difficulties in recruiting and retaining staff with skills and capacity to operate the digital systems currently in use and will be used in the near future. Many enterprises also lack regular practice using ICT software and systems, software applications that support digital transformation provide users with a comprehensive information system such as: data information Business to Business (B2B), Customer Relationship Management (CRM), Enterprise Resource Planning (ERP), finance, warehouse situation, etc. Approximately $30 \%$ of their state employees are familiar with, and use collaboration software such as virtual teams on daily basis. However, less than $20 \%$ of enterprises stated that they provide regular training or retraining on ICT-related skills for employees.

Strategy: The majority of enterprises surveyed have managed to incorporate digitalisation in their corporate or business strategy. However, only one in every ten enterprises has created a detailed roadmap or a coordination unit on digitalisation. In addition, around $10 \%$ stated the company's leaders are fully knowledgeable and aware of the importance, workings and implication of Industry 4.0.

Finance: The largest barrier to digital adoption for the electrical equipment manufacturing enterprises in Vietnam is finance. Only around $10 \%$ of enterprises surveyed reported significant investment in digitalisation in the last year and $10 \%$ indicated an intention to invest significantly in the next five years. The low investment among enterprises may be a result of insufficient available finance and a reluctance to invest in digitisation. Investing in new technology also involves significant uncertainty. Some enterprises declare there is a lack of trusted information available on the benefits of investing in new digital systems, and they lack the skills to identify the appropriate technology, especially for the initial phases of systems upgrades.

Smart production: Only $20 \%$ of surveyed enterprises adjudicated that interconnected production equipment used in their organisations allow for IT-access, and realtime information on the organisation's production. Around $10 \%$ are applying new technologies such as autonomous production lines, FMS (flexible manufacturing systems). About $20 \%$ of enterprises in manufaturing reported they regularly collect data from all stages of the production process and store it electronically. A smaller proportion (about 10\%) have real-time observation on production processes and have the capability to dynamically respond to changes in demand.

Infrastruction: Machinery and equipment is one of the factors directly involved in the production process, so the modernization of machinery and equipment or 
technological innovation is very important for every business. An electrical equipment manufacturing enterprise that wants to survive and develop needs to develop a plan for technological innovation. Scientific and technological progress and technological innovation will allow to improve product quality, create many new products, diversify products, increase output, increase labor productivity, rationally and economically use raw materials... As a result, it will increase competitiveness, expand markets, promote rapid growth and improve production and business efficiency. Scientific and technological progress, technological innovation is really the right direction of a potential electric equipment manufacturing enterprise. However, the survey results show that over $70 \%$ of enterprises are using old machinery, equipment and technology from countries such as Germany, Japan, Taiwan, China... because they have financial difficulties. Machinery and equipment in the production of electrical equipment are quite expensive, so enterprises cannot afford to buy new technological equipment and a high rate of automation. This has also been analyzed in the financial situation of the business above.

Overall assessment of the level of digital adoption of electrical equipment manufacturing enterprises.

\section{Electrical equipment manufacturing enterprises}

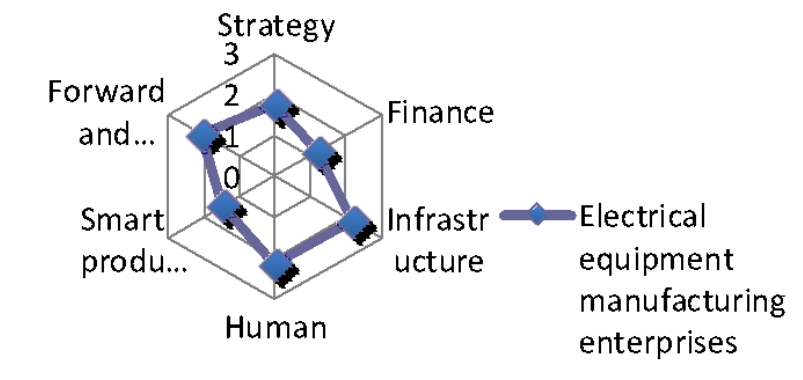

Figure 3. Digital adoption levels across dimensions in electrical equipment manufacturing enterprises

Note: Adoption level: Level 1 -Outsider; Level 2 Beginner; Level 3 - Intermediate; Level 4 Experienced; Level 5 - Pioneer/Expert

Source: Authors' survey results

From the above results, it can be seen that electrical equipment manufacturing enterprises are at the beginning of digital transformation. Overall, companies show the highest levels of willingness to adopt digital in their infrastructure and logistics (forward and backs linkages). However, companies are not better prepared financially, strategically and smartly.

However, it is necessary to appreciate the fact that digital transformation will become a "mandatory option" after the covid 19 pandemic. In order to comply with the new rotation of the technological revolution and the trend of industrial transformation, support the high-quality development of the new energy industry and facilitate the construction of smart energy, not only need to have a digital upgrade plan for the difficult points of the existing business, but also the evolving needs and digital transformation of energy businesses. Provide comprehensive end-to-end solutions and one-stop services for security compliance, cloud transformation, big data analytics, and AI applications. These trends mean that the management, operation, service and transaction models of power equipment manufacturers will undergo tremendous changes. Therefore, for electrical equipment manufacturing companies, digital transformation is not only using digital technology to enhance the technical added value of products, but also to achieve strategic business directions, operating model, organizational model and resource allocation. Most of the current electrical equipment manufacturing enterprises have not achieved the combination of the above four factors. The business model of enterprises is still the original "product-based sales", and the products themselves have not yet achieved technical added values.

\section{CONCLUSION AND RECOMMENDATIONS}

Lack of finance and insufficient information were found to be the main barriers to further digitalization at an enterprise level in the electrical equipment manufacturing enterprises. In particular, unclear economic benefits and uncertain impacts of technology adoption, and prohibitively high investments are the most important challenges for digitalisation in Vietnam, especially for small and medium enterprises.

On the other hand, technically developed large enterprises are pioneers in reform and opening up, developing high-class manufacturing industries and modern services. From starting to cooperate with sales partners, to integrating the resources of the upstream and downstream industry chains with suppliers, to now promoting the construction of a digital ecosystem open and help partners reach out internationally.

In digital transformation, transformation is the subject and digitization is the decisive factor. In other words, transformation comes first, and digitization is a tool of transformation. Enterprise transformation refers to the overall transformation of a company's long-term 
business direction, operating model and corresponding organizational methods, and methods of resource allocation. Enterprises need to review the process to make the necessary changes and choose the right technology for the business to transition to the digital transformation stage. This is an opportunity for businesses to look back to see if they are fully ready for digital transformation. The review allows the business to know which technologies need to be improved? Where is the "outdated" process that needs to be changed? Which stage is not ready and how to solve it? Then make the appropriate adjustments.

In enterprises, this job requires businesses to meet two factors: people and data. People are the most important factor. After all, technology is just a kind of support tool. The tool, no matter how smart it is, if the user does not have a change mindset, it cannot be effective. In other words, the success of digital transformation will be determined right in the mindset and vision from leadership levels to all levels of employees. Open communication is a key component of building a digital transformation process. Manager and employee feedback also plays an important role. Based on this feedback, leaders can make changes to optimize training effectiveness. To encourage constructive feedback, foster open discussions, open spirits, and collaboration. In order for all employees in the organization to understand that digital transformation is an important activity, leaders need to make it clear that digital transformation is a central strategy of the business. This needs to be demonstrated through the actions and plans of the company as well as the establishment of strategic teams in digital transformation.

In addition, data is an integral part of building digital transformation. If used well, data will create a springboard to help businesses transform digitally faster. However, in addition to analyzing existing data within the business, executives also need to pay attention to the data of their strategic partners as well as their competitors. Then, from there, they have an overview of the business value chain before entering the digital transformation race.

\section{For Businesses}

Leadership in charge of digital transformation: Many studies show that company employees are eager to see digital transformation starting from the company's leaders and directors. But today, many businesses still consider this to be the responsibility of the information technology, marketing or human resources department. However, a few production directors have been undertaking this digital transformation quite effectively and hopefully in the next time the remaining division directors such as sales director, finance director, etc. will apply this. Because changing and updating new trends will partly help refine the complicated and multi-step process, affecting the building of corporate culture.

Using technology as a service based on demand: Experts in the field say that in the budget and production engineering trends of the business, they are interested in creating efficiency and flexibility with their workloads as well as the ability to scale production rapidly based on business requirements. In the future, integrating smart production and green production has become an inevitable trend, it is necessary to use information technology and advanced production technology to reduce costs and increase efficiency, manage energy consumption quantity and energy revolution in production. Integrate cutting-edge technologies such as automation, lean manufacturing, energy efficiency and supply chain management, and apply them to the entire manufacturing life cycle (including R\&D, engineering, manufacturing, service, etc.) promote industrial enterprises to achieve high productivity, high quality, high efficiency, high flexibility and core competitiveness of high security enterprise through each digital transformation, and promote innovation, green development, coordination, openness and sharing of the electrical equipment manufacturing industry.

For the macro policy: Vietnam needs to accelerate the construction of "new infrastructure" such as 5G networks and data centers, which will certainly promote digital development. Digital transformation requires joint efforts of upstream and downstream enterprises in the industry chain. Small and medium enterprises need to join forces to jointly promote the digital transformation of the electrical equipment manufacturing industry and achieve sustainable and efficient development.

\section{LIMITATIONS OF THE STUDY}

The purpose of the study is to assess the digital transformation situation of electrical equipment enterprises, however, due to time and other resource limitations, the study only conducted a survey for equipment manufacturing enterprises. Electricity in Hanoi, the sample size of the survey is small, the respondents to the survey do not include the employees' assessment of the enterprise's digital transformation. Future research will attempt to overcome the limitations of this study.

\section{ACKNOWLEDGMENTS}

The authors gratefully acknowledge the contribution of Hanoi University of Science and Technology (HUST) under project number T2021-TT-013 


\section{REFERENCES}

[1] Alp Ustundag and Emre Cevikcan, Industry 4.0: Managing Digital Transformation. Springer Series in Advanced Manufacturing, 2018. DOI: 10.1007/978-3-319-57870-5. iscepi

[2] Bharadwaj, O. A. El Sawy, P. A. Pavlou, and N. V. Venkatraman, "Digital Business Strategy: Toward a Next Generation of Insights," MIS Quarterly, vol. 37, no. 2, pp. 471-482, 2013. istep.

[3] Chen, R. (Ronxin), Ravichandar, R., \& Proctor, D. (2016). Managing the transition to the new agile business and product development model: Lessons from Cisco Systems. Business Horizons, 59(6), 635-644. 10.1016/j.bushor.2016.06.005.

[4] Christian Matt, Thomas Hess and Alexander Benlian, "Digital Transformation Strategies", Business \& Information Systems Engineering, Vol. 57, No. 5, pp. 339 - 343, 2015. DOI: 10.1007/s12599-015-0401-5.

[5] Danang city Web portal (2020). https://danang.gov.vn/chinh-quyen/chi-tiet?id=2391 \&_c $=100000174$

[6] Guinan, P. J., Parise, S., \& Langowitz, N. (2019). Creating an innovative digital project team: Levers to enable digital transformation. Business Horizons, 62(6), $717-727$ https://doi.org/10.1016/j.bushor.2019.07.005.

[7] https://news.microsoft.com/vi-vn/2021/01/07/micro soft-sat-canh-cung-doanh-nghiep-viet-nam-hien-th uc-hoa-chien-luoc-chuyen-doi-so/

[8] Joakim Björkdahl, "Strategies for Digitalization in Manufacturing Firms", California Management Review:seppi2020, Vol. 62(4) 17-36

[9] K. Liere-Netheler, S. Packmohr, and K. Vogelsang, "Drivers of Digital Transformation in Manufacturing," in Proceedings of the Hawaii International Conference on System Sciences (HICSS), Honululu, USA, 2018.

[10]L. Caldwell, "How Digitalization Is Driving New Business Models for Manufacturers," Forbes, November 27, 2018, https://www.forbes.com/sites/lisacaldwell/2018/11/27/how-digitization-is-driving-n ew-business-models-for-manufacturers/\#87d70df6aa66;

[11]Matt, C., Hess, T., \& Benlian, A. (2015). Digital transformation strategies. Business \& Information Systems Engineering, 57(5), 339-343. https://doi.org/10.1007/s12599- 015-0401-5.

[12]O. Aguilar and J. Girzadas, "Save-to-Transform as a Catalyst for Embracing Digital Disruption,"
Deloitte,

April

2019,

https://www2.deloitte.com/content/dam/

Deloitte/us/Documents/process-and-operations/usglobal-cost-survey-2019.pdf;

[13]T. Hess, C. Matt, A. Benlian, and F. Wiesböck, "Options for Formulating a Digital Transformation Strategy," MIS Quarterly Executive, vol. 15, no. 2, pp. 123-139, 2016.

[14]Thomas M. Siebel (2019), Digital Transformation survive and thrive in an era of mass extinction, translated by Pham Anh Tuan. City General Publishing House. Ho Chi Minh, 2019.

[15] Vu Minh Khuong, Forecasting the impact of digital transformation on production and business results of 500 largest enterprises in Vietnam, Science and Technology Forum, 5/2019. https://a.vjst.vn/Images/file/2019/11/15-10A-2019. pdf.

[16] Vu Minh Khuong, Vietnamese enterprises before digital transformation: Understanding global trends and enhancing strategic thinking, 2019. https://a.vjst.vn/Images/Tapchi/2019/

11A/Pages\%20from\%20so11A-2019-pages-44-46. pdf 